\title{
Expression for Capacity of the Cone Type Converter of the Grain and Grain Products Sensor
}

\author{
Tulkun Zakirovich Nasirov, Patxulla Raxmatovich Ismatullayev, \\ Xamdam Shaymardonovich Jabborov \\ Faculty of Electronics and Automatics of the Tashkent State Technical University, Tashkent, Uzbekistan
}

\section{Email address:}

tulkunnasirov@yandex.ru (T.Z. Nasirov)

\section{To cite this article:}

Tulkun Zakirovich Nasirov, Patxulla Raxmatovich Ismatullayev, Xamdam Shaymardonovich Jabborov. Expression for Capacity of the Cone Type Converter of the Grain and Grain Products Sensor. International Journal of Sensors and Sensor Networks.

Vol. 6, No. 3, 2018, pp. 38-42. doi: 10.11648/j.ijssn.20180603.11

Received: December 30, 2018; Accepted: January 16, 2019; Published: January 31, 2019

\begin{abstract}
The expression for the cone type transformation moisture meter capacity for grain and grain products, using which we can measure the moisture more accurately has been considered. The analytical expression for the proposed ourselves sensor construction capacity having truncated cone shape has been given. The dependence of construction capacity on the geometrical sizes of conducting compartment (height, internal and external radiuses) has been investigated. The values of the capacity by optimization sizes of the construction conducting compartment have been presented. It has been defined that the maximal capacity of the sensor equals to $9.26 \mathrm{pF}$ and the capacity is nonlinear and decreasing monotonic down to zero.
\end{abstract}

Keywords: Grain Moisture, Capacity, Grain Sensor, Measure Accuracy

\section{Introduction}

It is known that in the storage, transportation, processing of grain and grain products the need for growing measure accuracy of grain moisture is increased. It is due to namely moisture influences essentially to qualitative and quantitative parameters in the grain processing technology: ones change from an optimal value even to $0.1 \%$ can lead to decreasing the top grade flour down to $0.8 \div 1 \%$, that as a result to essential damages will be caused. Therefore the special attention to measure of the moisture in the grain storage, transportation, processing is paid and this task is interesting [1].

To the present days the many methods had been investigated and in their base moisture meter series had been recognized between which the special attention to high frequency method is devoted. However, it should be noted that the recognizing devices where high frequency method is used have she essential disadvantage there the controlling accuracy has been decreased because of increasing the systematic part of errors. They deal with high clogging sensor because of electrodes directly in the grain divergence are accommodated [2]. In order to eliminate this disadvantage we must periodically to clean transformation removing its negative effect to the measuring process [3].

For solving this task, in particularly, in paper [4] the resistance transformation device scheme errors of contactless conductometric sensor had been analyzed and the possible measurements ranges of the investigating loose materials parameters had been defined. In paper [5] the parameters transformation for four elements electric scheme of accommodating contactless capacity sensor for conductometric measures of nonelectrical parameters had been considered where moisture control of process of the investigating materials drying had been done. And in paper [6] the efficiency which has high sensitivity and measures accuracy of string sensor had been investigated where it had been noted that one has the high sensitivity to the external effects leading too which lead to the essential measures errors.

The capacity micromechanical gyroscope accommodate schemes had been considered in paper [7] where an calculation algorithm for the output signal which is proportional to the informative parameter of capacity sensor had been proposed. In order to except the effect of parasite capacity and active resistances to use separate timely transformation channels of the informative parameter which can be used for construction sensitive element of capacity 
micromechanical gyroscopes had been proposed [8]. In paper [9] the classification signs allowing classification of methods for separate phase of channels had been proposed using which to synthesize a new methods for excepting errors dealing with parasite capacity cables is possible.

V. V. Kikot [10] had investigated possibility to decrease temperature errors measures of dynamic pressure by piezoelectric capacity sensors where using electric capacity scheme as informative parameter on temperature he discovered the correction possibility of the temperature errors by static temperature and thermal shock effects. In paper [11] the universal measuring transformation for differential capacity sensitive element which differs known later variants [12] by simplification of realization of main transformation algorithms using one the relative errors decreases down to $1 \%$ had been proposed.

It is known that in recognizing the high sensitivity measuring device which will been used for measuring and controlling the moisture the choice task of sensor, its action principles and construction is very important [13]. Thus, we must to know [14-17] previously what the sensor electrodes capacity ranges in?

In order to solve the mentioned above deficiencies and ensure requiring sensitivity in the present paper the sensor construction which, in our opinion, allows ensuring more accuracy measures the grain moisture has been proposed. In paper [18] the expression for the capacity of electrodes proposed there sensor construction had been obtained. As an logical continue of the provided in mentioned above paper investigations in the present paper the concrete numerical values of the capacity of the grain sensor have been presented and the dependence of construction capacity on its geometrical compartment sizes (height, internal and external radiuses) has been investigated.

\section{Expression for the Grain Sensor Capacity}

The capacity of any construction is defined by

$$
C=\frac{Q}{\phi}
$$

Where $Q$ is the charge accumulated in one compartment of sensor conductive part. It can be calculated conveniently taking into account homogeneity of distribution by total volume conductor, namely

$$
Q=\int \rho d V=\rho \int d V
$$

Where $\rho=$ const is the charge volume density.

The future actions stage is calculation of the volume of one compartment of conducting part of the grain sensor $V_{\text {ot }}$ (Figure 1). It can be done in the cylindrical coordinates system.

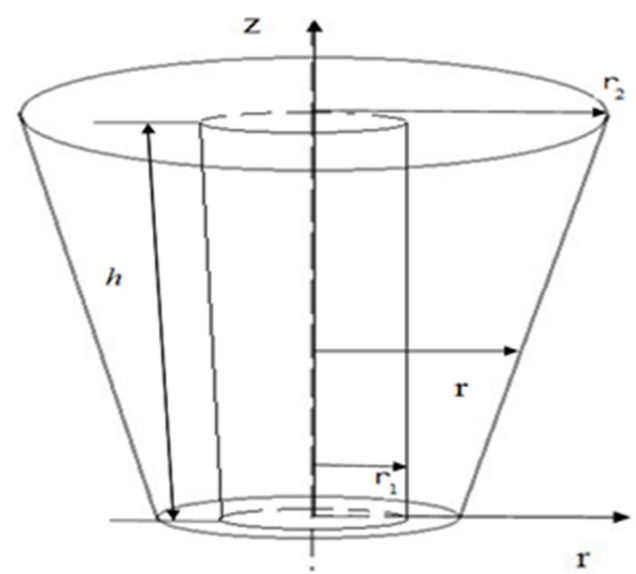

Figure 1. To the volume calculation of one compartment capacity of the cone type moisture converter.

For this purpose we shell calculate first volume of truncated cone $V_{u k}$ with bases radiuses $r_{1}$ and $r_{2}$ and also height $h$ :

$$
V_{u k}=\frac{\pi h}{3}\left(r_{1}^{2}+r_{1} r_{2}+r_{2}^{2}\right)
$$

Then we shell subtract from one the volume of hollow cylinder with base radius $r_{1}$ and height $h$

$$
V_{p s}=\pi r_{1}^{2} h
$$

And obtainedresultshelldivideto4 (the volume of one compartment equals to fourth of the obtained figure). In result we have

$$
V_{o t}=\frac{\pi h}{12}\left(r_{2}^{2}+r_{1} r_{2}+r_{1}^{2}\right)
$$

Now we shell calculate the potential of one compartment $\varphi_{\mathrm{ot}}$. It can be done in the cylindrical coordinates system too (Figure 2).

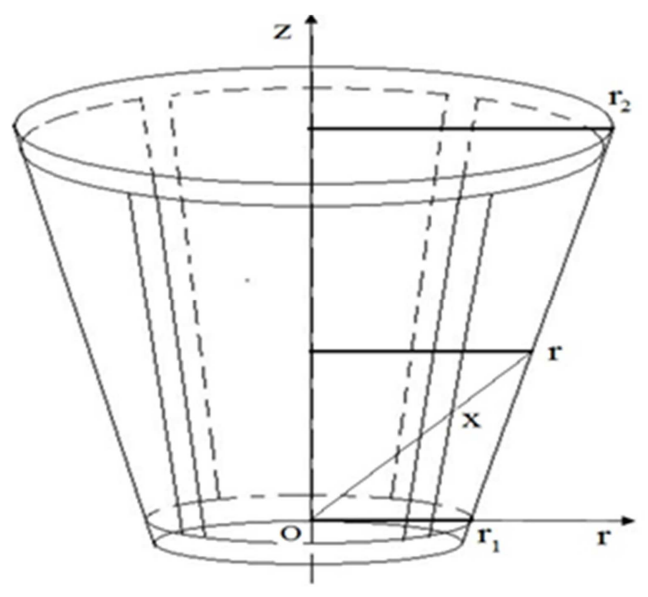

Figure 2. To the potential calculation of the cone type moisture converter.

$$
\phi=\int d \phi=\int \frac{1}{4 \pi \varepsilon_{0}} \frac{d Q}{x}=\frac{1}{4 \pi \varepsilon_{0}} \int \frac{\rho d V}{x}=
$$




$$
=\frac{\rho}{4 \pi \varepsilon_{0}} \int_{0}^{h} d z \int_{r_{1}}^{r} \frac{r}{x} d r \int_{0}^{\frac{\pi}{2}} d \psi=\frac{\rho}{8 \varepsilon_{0}} \int_{0}^{h} d z \int_{r_{1}}^{r} \frac{r d r}{\sqrt{z^{2}+r^{2}}}
$$

Integration on rgives

$$
\int_{r_{1}}^{r} \frac{r d r}{\sqrt{z^{2}+r^{2}}}=\left.\frac{1}{2} \sqrt{z^{2}+r^{2}}\right|_{r_{1}} ^{r}=\frac{1}{2}\left(\sqrt{z^{2}+r^{2}}-\sqrt{z^{2}+r_{1}^{2}}\right)
$$

In expression (4) variable $r$ can be found from this ratio (see, Figure 2)

$$
\frac{r-r_{1}}{z}=\frac{r_{2}-r_{1}}{h}
$$

From here

$$
r=\frac{r_{2}-r_{1}}{h} z+r_{1}
$$

Thus, the potential calculation leads to calculation of the difference of integrals $I_{1}$ and $I_{2}$ :

$$
\begin{gathered}
I_{1}=\int_{0}^{h} \sqrt{z^{2}+\left(\frac{r_{2}-r_{1}}{h} z+r_{1}\right)^{2}} d z \\
I_{2}=\int_{0}^{h} \sqrt{z^{2}+r_{1}^{2}} d z
\end{gathered}
$$

Integral function in the first integral of Exp.(5) can be presented as

$$
\sqrt{z^{2}+\left(\frac{r_{2}-r_{1}}{h} z+r_{1}\right)^{2}}=c \sqrt{(z+a)^{2}+b^{2}}
$$

Where

$$
a=\frac{r_{1}\left(\frac{r_{2}-r_{1}}{h}\right)}{1+\left(\frac{r_{2}-r_{1}}{h}\right)^{2}} ; \quad b^{2}=\frac{r_{1}^{2}}{1+\left(\frac{r_{2}-r_{1}}{h}\right)^{2}} ;
$$

After replacement $z \rightarrow z+a$ we have

$$
\begin{array}{r}
I_{1}=c \int_{a}^{h+a} \sqrt{z^{2}+b^{2}} d z=\frac{1}{2}\left(z \sqrt{z^{2}+b^{2}}+b^{2} \ln \left|z+\sqrt{z^{2}+b^{2}}\right|\right) \mid \begin{array}{l}
h+a \\
a
\end{array}=\frac{1}{2} c\left[(h+a) \sqrt{(h+a)^{2}+b^{2}}+\right. \\
\left.+b^{2} \ln \left|h+a+\sqrt{(h+a)^{2}+b^{2}}\right|-a \sqrt{a^{2}+b^{2}}-b^{2} \ln \left|a+\sqrt{a^{2}+b^{2}}\right|\right]
\end{array}
$$

Calculation of the second Exp. (5) gives

$$
I_{2}=\left.\frac{1}{2}\left(z \sqrt{z^{2}+r_{1}^{2}}+r_{1}^{2} \ln \left|z+\sqrt{z^{2}+r_{1}^{2}}\right|\right)\right|_{0} ^{h}=\frac{1}{2}\left(h \sqrt{h^{2}+r_{1}^{2}}+r_{1}^{2} \ln \left|h+\sqrt{h^{2}+r_{1}^{2}}\right|-r_{1}^{2} \ln r_{1}\right)
$$

Finally, after substituting Exps. (2), (6) and (7) to Exp. (1) for one compartment potential we obtain

$$
\phi=\frac{\rho}{8 \pi \varepsilon_{0}}\left(I_{1}+I_{2}\right)
$$

Then using Exps. (1)-(3) and (8) for the capacity of one compartment for conducting part of the sensor we have

$$
C=\frac{\frac{\pi h}{12}\left(r_{2}^{2}+r_{1} r_{2}-2 r_{1}^{2}\right)}{\frac{I_{1}+I_{2}}{8 \pi \varepsilon_{0}}}=\frac{2 \pi^{2} \varepsilon_{0} h\left(r_{2}^{2}+r_{1} r_{2}-2 r_{1}^{2}\right)}{3\left(I_{1}+I_{2}\right)}
$$

\section{Compartments Connection Variants of the Electrodes}

Now let us consider all possible variants of connecting of the studying device to the electric circuit. For this purpose we shell sign each compartment in the device by $1,2,3$ and 4 (see, Figure 3).

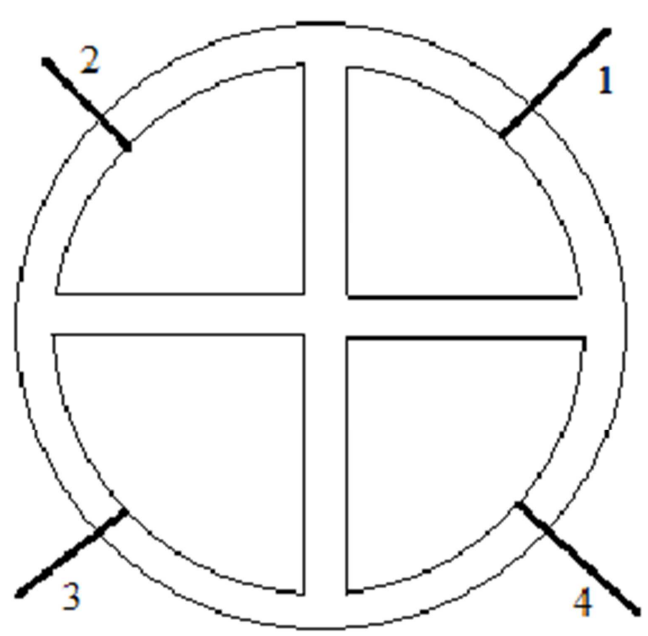

Figure 3. The scheme of quarter compartments of the grain sensor elements.

First case. One phase to compartments 1 and 2 and other to ones 3 and 4 willbeenconnected. This variant is equivalent to the parallel connection of two capacitors with $C(9)$. Then the resulting capacity equals 


$$
C_{p a r}=2 C
$$

Second case. One phase to compartments 1 and 3 and other to ones 2 and 4 will been connected. This variant is equivalent to the consistent connection of two capacitors with $C(9)$. Then the resulting capacity in this case equals

$$
C_{\text {con }}=\frac{C}{2}
$$

Third case. One phase to compartment 1 and other to ones 2, 3 and 4 will been connected. This variant is equivalent to consistent connection of two capacitors $C$ and $3 C$. The resulting capacity in last case equals

$$
C_{m i x}=\frac{3 C}{4}
$$

\section{Numerical Results}

The dependence of the grain sensor capacity on parameters $h, r_{1}, r_{2}$ in Figures $4-6$ have been presented. It is seen from Figure 4 that the capacity is nonlinear and decreases monotonic down to zero in $r_{1} \rightarrow r_{2}$. The most capacity value which equals approximately to $9.26 p F$ reaches by $r_{1} \rightarrow 0$.

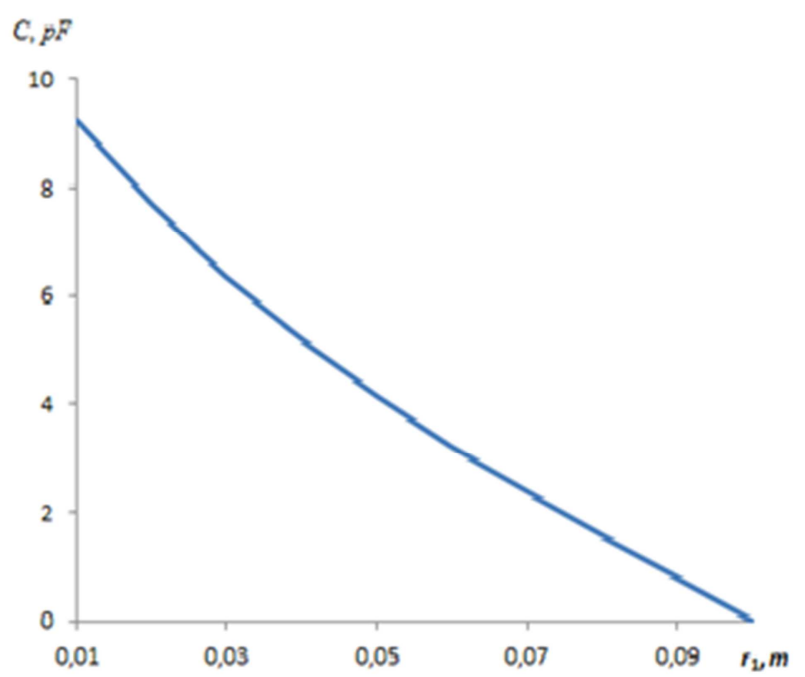

Figure 4. The dependence for capacity $C$ of one grain sensor compartment on parameter $r_{1}$ by fixed values of parameters, $h=0.1$ meter, $r_{2}=0.1$ meter.

About the same picture in dependence of capacity on parameter $h$ is observing (see Figure 5). However, in this case on range of $0 \leq h \leq 2 \mathrm{sm}$ the capacity does not changing practically taking the most value approximately $4.15 \mathrm{pF}$ and nonlinearity is manifesting stronger in comparison of the dependence on $r_{1}$. As to the dependence of the capacity on parameter $r_{2}$ then it takes zero value in $r_{2}=r_{1}$ and increases practically linearly by growing values of parameter $r_{2}$ (see Figure 6).

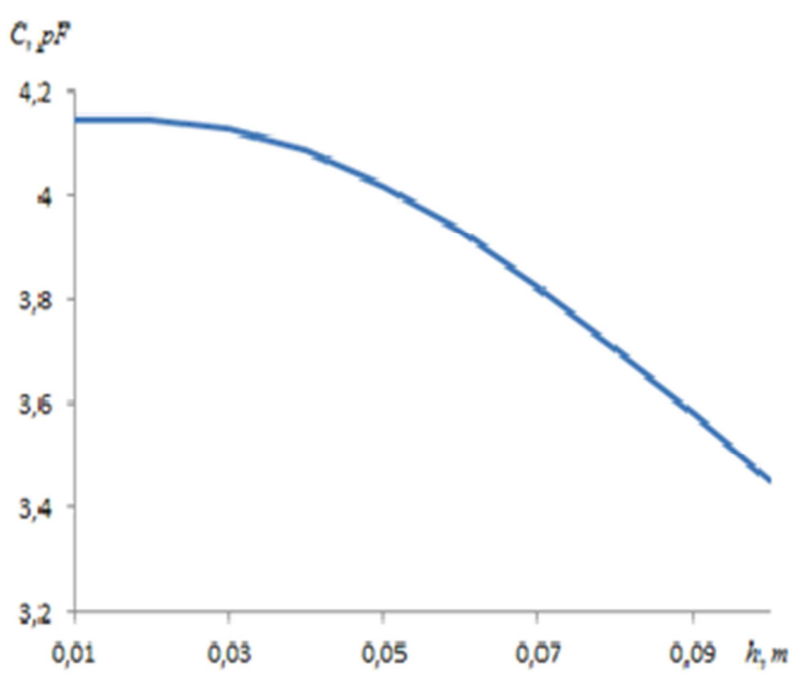

Figure 5. The dependence for capacity $C$ of one grain sensor compartment on parameter $h$ by fixed values of parameters, $r_{1}=0.05$ meter, $r_{2}=0.1$ meter.

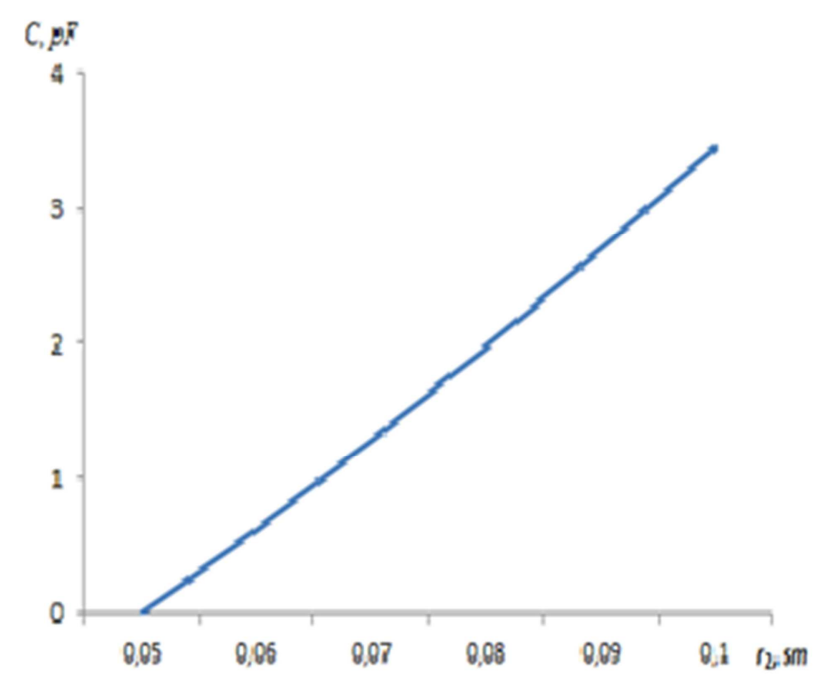

Figure 6. The dependence for capacity $C$ of one grain sensor compartment on parameter $r_{2}$ by fixed values of parameters, $h=0.1$ meter, $r_{1}=0.05$ meter.

Finally, let us consider the variant corresponding to more real device geometrical sizes: $h=10 \mathrm{sm}, r_{1}=5 \mathrm{sm}, r_{2}=10 \mathrm{sm}$. Substituting these values to Exps. (6)-(9) we have

$$
C=3.45 \mathrm{pF} ; C_{\mathrm{par}}=6.9 \mathrm{pF}, C_{\mathrm{con}}=1.726 \mathrm{pF}, C_{\mathrm{mix}}=3.45 \mathrm{pF}
$$

\section{Conclusion}

Thus, the following conclusions from the results of provided investigations can be stated:

the first, the expression for the capacity for one of four compartments of grain sensor which is expressed through height and internal and external radiuses has been obtained;

The second, the most (double) construction capacity in case of connection of these compartments in pairs and parallel is reached;

The third, the least (double) construction capacity in case of connection of four compartments crosswise is reached;

The fourth, the intermediate capacity we can obtain by mixing connection of construction compartments. 
Finally, the investigations of dependence of capacity values of the grain sensor on parameters $h, r_{1}, r_{2}$ have showed that the most capacity (approximately $9.26 \mathrm{pF}$ ) reaches by $r_{1} \rightarrow 0$ and one decreases monotonic down to zero value. As the dependence of capacity on parameter $h$ then the nonlinearity manifests essentially in comparison of the dependence on $r_{1}$ and it in range $0 \leq h \leq 2 \mathrm{sm}$ accepting the most value $4.15 p F$ does not changing. However, the dependence of capacity on parameter $r_{2}$ here, visa versa, one groves up linear practically.

Calculation of numerical values of capacity by real geometrical device sizes $h=10 \quad \mathrm{sm}, \quad r_{1}=5 \quad \mathrm{sm}$, $r_{2}=10$ smgives: $C=3.45 p F ; \quad C_{\text {par }}=6.9 p F, \quad C_{\text {con }}=1.726 p F$, $C_{\text {mix }}=3.45 \mathrm{pF}$.

It follows from the analysis of provided investigations results that proposed construction to the measuring grain sensor moisture device which, in our opinion, allows to solve the task of contamination eliminate of the sensor can be recognized. It is extremely important in measuring of the moisture in the grain storage, transportation, processing.

\section{References}

[1] Berliner M. A. Electrical measurements, automatic control and moisture regulation (in Russian). -Moscow: Energiya, $1965,-488 \mathrm{p}$.

[2] Berliner M. A. Moisture measurements (in Russian). Moscow: Energiya, 1973, -400 p.

[3] Ismatullayev P. R. Methods and technical equipments for moisture controlling in cotton oil production (in Russian). Tashkent: Fan, 1983, -108 p.

[4] Grachev A. V. The errors analysis of measurements scheme for resistant transformation without contact conduct metric sensor (in Russian) // Izmereniye, monitoring, upravleniye, kontrol, 2016. № 2(16). P. 96-102.

[5] Grachev A. V., Churakov P. P. Parameters transformation of without contact capacity sensors for conductmetric measurements (in Russian) // Izvestiya Samarskogo nauchnogo sentra rossiyskoi akademii nauk, 2016. V.18. № 4(47). P. 1363-1366.

[6] Antonets I. V., Borsoyev V. A., Katsura A. V., Stepanov S. $\mathrm{M}$. Investigation weight meter construction base on the circle elastic sensitive element and secondary string sensor (in Russian) // Sibirskii jurnal nauki i texnologii, 2017. V.18. № 2. P. 358-366.
[7] Arbuzov V. P., Mishina M. A. Measurement transformations for capacity micromechanical gyroscopes (in Russian) // Izvestiya vuzov. Priborostroyeniye, 2017. V.60. № 12. P. 1138-1145.

[8] Arbuzov V. P., Mishina M. A., Belintseva P. N., Anan'inaI. Yu. Measurement chains of high temperature pressure capacity sensors (in Russian) // Izmereniye, monitoring, upravleniye, kontrol, 2015. № 1(11). P. 81-88.

[9] Arbuzov V. P., Mishina M. A., Belintseva P. N. Systematization of channel phase separated method for capacity sensors measurement chains (in Russian) // Izvestiya visshix uchebnix zavadenii. Povoljskii rayon. Texnicheskiye nauki, 2017. № 1(41). P. 85-95.

[10] Kikot V. V., Malanin V. P., Sherbakov M. A. Correction for temperature errors of pezoelectric sensor of dynamic pressure in thermal shock conditions (in Russian) // Izvestiya visshix uchebnix zavedenii. Povoljskii rayon, 2016. № 3(39). P. 105113.

[11] Karpov V. A., Xananov V. A. Universal measuring transformation for the differential capacity sensitive element (in Russian) // Vestnik GGTU imeni P. O. Suxogo, 2014. № 1. P. 91-96.

[12] Frayden J. Modern sensors: the directory (in Russian). Moscow: Texnosfera, 2005. -592 p.

[13] Romanov V. G. Moisture meter test of hard substances (in Russian). -Moscow: Izdatel'stvo standartov, 1983. -176 p.

[14] Krichevskii E. S. and at el. Hard and loose substances moisture control (in Russian). -Moscow: Energoatomizdat, $1986,-136 \mathrm{p}$.

[15] Men'shikov A. M. The methodical errors testing dielcometric moisture meters in using of moisture imitators (in Russian) // Izmeritel'naya texnika, 1996. № 1. P. 49.

[16] Royfe V. S. The decreasing way of methodic errors of moisture by first capacity transformations (in Russian) // Izmeritel'naya texnika, 1996. № 7. P. 85.

[17] Jejora A. A. Capacity transformations and their calculation methods (in Russian). -Minsk: «Belarusskaya nauka», 2008, -p. 352 .

[18] Ismatullayev P. R., Nasirov T. Z., Jabborov X. Sh. Expression for the capacity of the cylindrical converter of the grain and grain products sensor // Tenth world conference on intelligent systems for industrial automation. -Tashkent, Uzbekistan. 25-26 October, 2018. P. 388-390. 